\title{
Study on Multicultural Education Qualities in Chinese Ethnic Universities - Taking the Pre-Service Teachers of Yanbian University as an Example
}

\author{
Jin Hongpei, Jin Shumei \\ Yanbian University, Yanji, China
}

\begin{abstract}
Ethnic education is in a leapfrog development in China now. At present, the issues of the bilingual education and ethnic multicultural curricula are the main problems in ethnic schools. The survey showed that the teachers of primary and middle schools agreed with the importance of the multicultural education, but most teachers did not know much about the knowledge or have abilities of multicultural educating. As an ethnic university, Yanbian University constructs the teacher education program that includes multicultural curricula and security systems. The teacher education program can improve the pre-service teachers' multicultural qualities a lot.
\end{abstract}

Keywords: ethnic university, pre-service teachers, teacher education program, multicultural education qualities

\section{Introduction}

At the end of 1980s, some Chinese scholars realized the importance of teachers' multicultural teaching qualities of ethnic education. The ethnic education in China has improved a lot since then. However, there are still lots of problems of the bilingual education and multicultural curricula in ethnic schools. So, it is necessary for the teachers to have the abilities to deal with the relationships between mainstream culture and ethnic culture (James, 2008). That is also the ethnic teachers' professional standards. The action research was used in Yanbian University to develop the multicultural education.

\section{The Multicultural Teaching Qualities}

\section{The Contents of the Multicultural Teaching Qualities}

The teachers' multicultural teaching qualities mainly include knowledge, emotion, and skills that can deal with the relationships between mainstream culture and ethnic culture (Chen, 2000). These qualities can help teachers to develop students' identification of minority ethnic groups, the ethnics' students' self-esteem, and confidence to gain achievements at school.

\section{Knowledge Goal of Multicultural Teaching Qualities}

The teachers need to have multicultural teaching knowledge, and know about ethnic history, culture, and the ethnic students' learning styles. Emotion goal of multicultural teaching qualities: The teachers have to appreciate different cultures, and respect the behaviors and habits of the ethnic students. Skill goal of

Jin Hongpe, Ph.D., professor, College of Liberal Arts, Yanbian University.

Jin Shumei, Ph.D., professor, College of Education, Yanbian University. 
multicultural teaching qualities: Teachers must realize that different culture backgrounds can make great difference to students' behaviors, learning styles, and communicating styles. They also have to be able to deal with those differences.

The multicultural teaching qualities are very helpful for teachers to understand the students' behaviors and evaluate the students' abilities in key learning areas. Cultivating the students' self-esteem and confidence is the base for them to gain achievements at school, so the teacher education program should be combined with dialectics and cross-cultural perspective (Wan, 2014).

\section{The Challenge of Multicultural Education Qualities for Teachers in Primary and Middle Schools in Yanbian Chinese-Korean Region}

For a long time, according to the teaching theory based on abilities, the teacher education program only focused on the knowledge and abilities of their own majors. However, they did not pay much attention to the cultivation of students' humanity qualities or the value of the scientific spirit. The contents of the teacher education program only showed the importance of knowledge and skills. The assessments of the teacher education program also just emphasized knowledge and skills.

There are 36.3\% Chinese-Korean (43\% Chinese-Korean of China) in Yanbian Chinese-Korean Ethnic Region. Yanbian Chinese-Korean Region is also a neighbor of Russia, Japan, and North Korea. At the context of process of economic globalization, the close economic, social, and intercultural communication is a typical feature here. In Yanbian Chinese-Korean Region schools, the students are from different culture backgrounds, they consider same issues differently because of their particular culture values.

A survey that included questions about the knowledge, attitude, and abilities of multicultural education was designed by some scholars from Yanbian University in 2013. The survey data showed that most Chinese-Korean teachers in ethnic schools agreed with the importance of the multicultural education, but few of them had the knowledge and skills. A question from the survey was "An ethnic teacher should know both the Korean culture and Chinese culture well." There were $83 \%$ of the ethnic teachers agreeing with it. However, the survey showed that $98 \%$ of the teachers did not know much about the knowledge or had abilities of multicultural educating, and $93 \%$ of the teachers knew little about how to design and carry out the curricula of multicultural educating.

Therefore, how to improve the ethnic teachers' qualities on multicultural teaching is a serious problem in Chinese-Korean teacher education programs.

\section{The Courses to Cultivate the Multicultural Education Qualities of Pre-Service Teachers in Yanbian University}

\section{The Multicultural Education Courses Were Guaranteed Because the Closed Teacher Education Model Was Replaced by the Open Model in Yanbian University in 2005}

Closed teacher education model had lasted for a long period since the teacher education major started in 1949 in Yanbian University. The pre-service teachers were cultivated in each specialized department. The curricula system for pre-service teachers under the closed teacher education model was constructed by four parts: education foundation, educational psychology, subject instructional methods, and education internship. The credits of the teacher education curricula were from 15 to 20 in total. The period of the educational internship was a month. The levels of teaching abilities and humanity qualities were very low in the closed 
teacher education background. There were also "blank" areas in the field of ethnic teacher education and in the special professional standards for the ethnic teachers. Students only focused on their majors in the closed normal education model, while teaching training and literacy were obviously ignored.

In 2005, the open model for pre-service teacher training was constructed in order to improve the teaching abilities and humanity qualities. The open model is to teach students major knowledge in their first two years and then give them professional trainings about education in their last two years. In the first two years, all students have to study their major knowledge and liberal arts. In the fifth semester, students who have finished all required credit hours in their major and liberty arts will choose the field of the teacher education program or the field of their major research. Teachers' education class hours and credits are guaranteed in the open model. The curriculum confliction between the teacher education and major research is also resolved.

The multicultural curricula system was developed under the open model in Yanbian University in 2010. It is aimed to cultivate the multicultural education qualities of the ethnic pre-service teachers.

\section{The Goal of the Multicultural Curricula Is to Develop the Students' Abilities of Managing the Cultural Conflicts Under the Multicultural Background}

In order to reach the goal, the students have to learn to appreciate the Korean culture and the multiple cultures both about China and the world. They also have to understand the different natural ways of reaction that people have when they face problems because of different cultural backgrounds.

The multicultural curricula system bases on the Korean cultural and regional features. Most Chinese-Koreans in China live in Yanbian, so the Korean traditional culture is the mainstream culture there. Yanbian University is located in the capital of Yanbian Korean Region, so it is important for Yanbian University to help with the ethnic cultural inheritance and development. On the location, Yanbian is very close to the national boundaries of China, Russia, Japan, and Korea, so Yanbian is serving as a unique transport to North and East Asia. That is also the reason why Yanbian has so many different cultures.

The multicultural curricula base on the Korean culture and the Yanbian's location. All of the students should learn about the culture, contributions, and the history of the Chinese-Koreans as well as some other ethnic cultures that students are interested in.

There are three terms in a school year in the open model of the teacher education program. There is a one-month short term, which is from the beginning of July to the beginning of August. Fitty percent of the multicultural curricula are in the short term.

\section{Different Parts of the Multicultural Curricula System Are Based on the Special Environment}

The multicultural curricula system should contain the characteristics of Korean traditional culture and the social development of Russia, Japan, North Korea, and South Korea.

According to the Korean cultural characteristics and Yanbian's location, the multicultural curricula system is constructed by three parts in Yanbian University.

The first part is the multicultural knowledge curricula, including the Introduction of Multicultural Education, Korean History and Culture, Cultural Geography of Yanbian Korean Region, Comparing the Political System of Northeast Asia, the Study on Chinese Novels in South Korea, etc..

The second part is language curricula. The language environment is good for students to practice Korean and Russian in Yanbian University. Some classes can be taught in Chinese or Korean, because $50 \%$ of the students and $70 \%$ of the teachers are Chinese-Korean. Language is an external feature of a person's thoughts 
and culture background. The language curricula include one compulsory class and four optional classes. In order to understand the Korean culture further, Korean class is a compulsory course for students except the Chinese-Korean students. Russian, Japanese, Multiple Languages and Cultural Resource, the Study on Misunderstanding the Cultural Communications Between China and Korea are the four optional classes. They are developed to cultivate the communicating abilities and the multicultural awareness.

The third part is ethnic curricula. The ethnic curricula include the Introduction of Korean Folklore, the Study on the Relation Between Health and Korean Traditional Food, the Study on the Culture of TaiChi and Eastern Asian Dance, Korean Traditional Sports Culture, Study on the Living Culture of the Koreans, How Chinese culture and Western Culture Influence People's Health, etc..

Multicultural curricula include the three parts above. The three parts cover the fields of politics, history, geographic, sports, arts, constructions, language, and culture. Students must get at least 16 credits from these curricula.

\section{Implementation Approaches}

The approaches to multicultural curricula were brought up by James A. Banks who was one of the most popular scholars in the multicultural education field. There are four approaches according to professor James (1998): the additional approach, the contribution approach, the transformation approach, and the social action approach. The contribution and additional approaches were further developed on the base of professor James' theory and the situation of Yanbian University.

\section{The Additional Approach}

The additional approach means typical courses and series of lectures. There are three types of ways in this approach: 1 . In the first type of way, 21 courses are open in the short term that is from the beginning of July to the beginning of August for all students; 2. In the second type of way, every department has their own multicultural curricula that are related to the discipline program in the spring and autumn term. For example, students study Comparison on Marriage and Family Law in the Department of Law, Multicultural Nursing in Nursing Colleges, etc.. Eleven courses are opened by the departments in total. In the two ways above, cooperative-learning model is used in classroom teaching to teach students the skills of listening patiently and communicating nicely. The skills are helpful to students to form active partnerships; And 3. The third type of way is to give series of lectures to students in their spare time. The special fund is provided by Yanbian University to support the departments, so that they can invite some leading experts in China to give lectures about the multicultural education. At least 30 lectures have to be held every term, such as lectures about Korean Recent Education Development Tendency and the Historical Problems of the Chinese-Koreans' Migration.

\section{The Contribution Approach}

The multicultural education is carried out by series of activities, such as the Korean Regional Day, the Korean Traditional Dress Festival in June, the Korean Traditional Food Festival in October, the Korean Old People's Festival in August, the Korean Anti-Japanese Heroes Day, etc..

The Korean history, culture, and the contribution to the world can be demonstrated intuitively by series of activities. These kinds of activities are helpful to students from different cultural backgrounds to learn about Chinese-Koreans, to appreciate the Korean culture, and to build ethnic identity in the end. 


\section{The Social Action Approach}

The ideas of multicultural education were carried out in the internships for pre-service teachers in 2010 . Professor Sleeter from the USA who studied multicultural education said that it was very important for student teachers to accept and endorse the multicultural education by communicating with students and their parents coming from different culture backgrounds (Sleeter, 2007). The multicultural knowledge they learned from the communication could help them recognized the reason why students could not get used to the school life. The student teachers with multicultural education abilities could help the students and their parents to think about the conflictions in a cross-cultural perspective. The student teachers should also keep close to a student for a term to understand more and experience his/her culture. In the ethnic teacher education program, besides the regular tasks that the student teachers should complete, they were also required to hand in a report based on the investigation. In the report, they should write about some differences of the students from different cultural backgrounds, and explain some behaviors that were affected by the culture backgrounds, such as the students' learning styles and the interactions among people. The investigation report based on the students' different culture backgrounds could help the student teachers to improve their knowledge and skills of multicultural teaching.

\section{Security Systems to Develop Multicultural Education}

\section{The Least Credit Standards for High Professional Talents}

In order to cultivate high professional talents with cross-cultural ability, Yanbian University set up the least credit standards in curriculum modules. According to the standards, every student must gain 10 credits in multicultural curriculum modules.

An amount of special fund has been launched to develop the multicultural curricula every year since 2000 . Every multicultural curricula teacher can gain about $\$ 5,000$ in the first three years of teaching.

\section{The Supervision System for the Improvement of the Qualities of Multicultural Curricula}

The principle of Yanbian University will invite some professors to check the course descriptions, other orientation materials, course outline, and reference books. The professors will also attend the students' classes, and discuss some questions with the students. Some other scholars will go to elementary schools or middle schools to learn about the ethnic teachers' problems with the multicultural education.

In order to let the student teachers carry out multicultural ideas and teaching skills in elementary schools and middle schools, Yanbian University and the ethnic schools in Yanbian Chinese-Korean Region signed the agreement on cultivating teachers' multicultural qualities. There were eight ethnic schools that joined the program. According to the agreement, during the internship, the student teachers must learn about teaching knowledge, especially on how to communicate with the students and their parents from different culture backgrounds. The student teachers also need to share the multicultural ideas, multicultural knowledge and skills with other teachers and the students' family members from the ethnic schools.

\section{Conclusion}

Improving pre-service teachers' multicultural education qualities is a great goal of the ethnic teacher education program in Yanbian University. Yanbian University is getting higher social appraisals, enhancing the school popularity, and attracting more excellent students to Yanbian University because of the multicultural 
education. Students learn to respect the multiple cultures form right ethnic identity, and understand the different ways of thinking and behaving styles of students that are from different culture backgrounds in the ethnic teacher education program. Almost every graduate from Yanbian University have got favorable comments from the employing units, because they have much multicultural knowledge and cross-cultural communicating abilities.

\section{References}

Chen, M. (2000). The idea and practice of multicultural curricula. Taipei: Normal Education Publishing Co., Ltd..

James, A. B.( 2008). Multicultural education: Issues and perspectives. (Z. L. Chen, Trans.). Taipei: Psychological Publishing Co., Ltd..

James, A. B. (1998). Introduction to multicultural education. (P. Y. Li, Trans.). Taipei: Public Translation Co., Ltd..

Sleeter, C. E. (2007). Facing accountability in education democracy and equity at risk. New York: Teachers College Press.

Wan, M. G. (2014). Research comparatively on multicultural education. Beijing: Ethnic Publishing Co., Ltd.. 